\title{
PRESENCE OF FOLIAR DISEASES CAUSED BY FUNGI IN MANGROVES ON THE EAST COAST OF PENINSULAR MALAYSIA
}

\author{
SAHIBU, A. ${ }^{1}$, SITI NORDAHLIAWATE, M.S.S. ${ }^{2}$ and ABDULLAH, M.M..$^{1 *}$ \\ ${ }^{1}$ Faculty of Science and Marine Environment, Universiti Malaysia Terengganu, \\ 21030 Kuala Nerus, Terengganu \\ ${ }^{2}$ Laboratory for Pest, Disease and Microbial Biotechnology, Faculty of Fisheries and Food Sciences, \\ Universiti Malaysia Terengganu, 21030 Kuala Nerus, Terengganu \\ *E-mail:maizah@umt.edu.my
}

Accepted 30 November 2020, Published online 25 December 2020

\begin{abstract}
Mangrove health is very important for the ecosystem to survive the challenges and threats due to climate change and anthropogenic pressures. However, unhealthy mangroves due to pathogenic fungi causing diseases may demote the survival rate of younger plants to grow and information on the status of foliar disease incidence is limited. This study aimed 1) to observe the foliar disease symptoms that occurred on Rhizophora apiculata and Avicennia marina and 2) to identify the fungi isolated from the symptomatic leaves. Samples were collected from the mangrove area located in Universiti Malaysia Terengganu (UMT) campus, along the South China Sea. All isolates were identified based on their morphological characteristics. A total of five foliar disease symptoms were observed namely black leaf spot, grey leaf spot, leaf rot, sunken leaf blight, and anthracnose. Rhizophora apiculata has a greater number of leaf spots than A. marina. Four genera of fungi; Pestalotiopsis sp., Curvularia sp., Colletotrichum sp. and Rhizopus sp. were successfully isolated from symptomatic leaves where the most dominant was Pestalotiopsis sp. to both mangrove species. This finding highlights the need to obtain the status of foliar diseases and their impact on the resilience of mangroves in Malaysia.
\end{abstract}

Key words: Fungi, mangrove health, Foliar disease, Rhizophora apiculata, Avicennia marina, South China Sea

\section{INTRODUCTION}

Mangrove ecosystem plays an important role in balancing the environment quality of marine and coastal environment. It regulates the climate by capturing and storing a high amount of carbon into the mangrove sediment through carbon sequestration (Mcleod et al., 2011; Siikamaki et al., 2012). An unhealthy mangrove ecosystem could affect the overall ecosystem balance (Purwaka \& Siregar, 2012). Mangrove trees are structurally and functionally unique compared to other tropical forests. The unique characteristics of mangrove trees are their adventitious aerial roots, viviparous embryos, complex root tissues, and the presence of salt glands on the leaf surface (Alongi, 2009). Meanwhile, the leaf is considered an important organ in the plant where it enables photosynthesis,

\footnotetext{
* To whom correspondence should be addressed.
}

transpiration, and other biological processes to occur (Steven, 2012). Moreover, the presence of salt glands on mangrove leaves plays an important function to remove excess salt from their tissue (Kothari et al., 2002). Besides, the leaf is the largest component of mangrove litter (Abdullah et al., 2010), which becomes an important component in the mangrove food web.

Fungi that inhabit the mangrove ecosystem is known as manglicolous fungi (Kohlmeyer, 1969; Jones \& Hyde, 1988, 1990; Jones \& Kuthubutheen, 1989). They include mostly marine fungi and a small group of terrestrial fungi that can be categorized into saprophytic, parasitic, and symbiotic fungi. Parasitic fungi may infect the plant's organs such as leaf, stem, and fruits. The spore which is the reproductive body of fungi disperse from one host to another through animals, insects, wind, water, and soil (Agrios, 2005), and attach to the susceptible leaf surface and germinate 
under favorable conditions. After germination, the hyphae developed and penetrated the leaf cell to obtain nutrients and thus, damage the surface of the leaf by creating an abscission layer in the form of spots or lesions. As a result, the photosynthesis and transportation rate of the leaf decreases as the growth of fungus damages the chlorophyll content and reduce the number of stomata on the leaf (Larsen, 2017). This will eventually minimize the light absorption mechanism which is an important process for plant growth.

An infected leaf can be identified and categorized based on the symptom appearance such as shape, color, and size. The symptoms could appear as spots, blights, rusts, and mildew following how the pathogen species invade the leaf tissue (Horst, 2008). The common foliar disease observed is leaf spot and it can be categorized and named after the fungus or the color of the spot, such as black leaf spot (Horst, 2008). Other popular foliar diseases such as anthracnose, scab, and blotch. The leaf spot disease had been observed on the red mangrove in Puerto Rico mangrove forest where Anthostomella spp., Cercospora rhizomorphae, and Pestalotia disseminate were identified (Stevens, 1920). In Florida red mangrove, Cercospora spp. was isolated from the leaf spot symptom (McMillan, 1964). Recently, Rossi et al. (2017) had discovered Pestalotiopsis species infecting the Rhizophora mangle in The Bahamas mangrove forest. However, in Malaysia, fungi occurrence in mangroves had been reported from sediment (Alias et al., 2010) and little information on foliar diseases. This study aimed to observe the foliar disease symptoms that occurred on Rhizophora apiculata and Avicennia marina and to identify the fungi isolated from the symptomatic leaves, based on their morphological characteristics.

\section{MATERIALS AND METHODS}

\section{Samples collection}

Thirty $(\mathrm{n}=30)$ symptomatic mangrove leaves from each six $R$. apiculata and $A$. marina trees $(\mathrm{n}=6)$ were hand-picked randomly and stored in a zip-lock plastic bag with silica gel. The sampling was done during low tide in a mangrove forest located in Universiti Malaysia Terengganu (UMT) campus (Figure 1).

\section{Symptoms observation under Scanning Electron Microscope (SEM)}

SEM was used to reconfirm the causal agent of the symptomatic mangrove leaves by detecting the physical presence of fungi such as mycelia, hyphae, and fruiting bodies. The leaves with the disease symptoms were cut into smaller square fragments $(0.5 \mathrm{~mm} \times 0.5 \mathrm{~mm}$ approx. $)$ by using a sterile sharp razor blade, then were fixed with $2.5 \%$ of glutaraldehyde (GA) in $0.1 \mathrm{M}$ sodium cacodylate buffer ( $\mathrm{pH} \mathrm{7.2)} \mathrm{for} 4 \mathrm{hr}$, rinsed three times with ethanol solution and post-fixed the samples with $2 \%$ osmium $0.1 \mathrm{M}$ sodium cacodylate buffer $(\mathrm{pH}$ 7.2) for 4 hrs. Next, the samples were dehydrated to remove excess water by using a crescent series of ethanol and immersed in hexamethyldisilazane (HMDS) solution for 10 mins before mounted on the Scanning Electron Microscope (SEM) stubs (Purkayastha \& Pal, 1998). The samples then sputtercoated with gold and examined under SEM.

\section{Fungal isolation and identification}

Potato Dextrose Agar (PDA) media (with antibiotics) was used to isolate fungi. Leaf samples with lesions were cut into small square fragments and immersed in $70 \%$ ethanol and $4 \%$ sodium hypochlorite $(\mathrm{NaOCl})$ to remove unwanted micro-

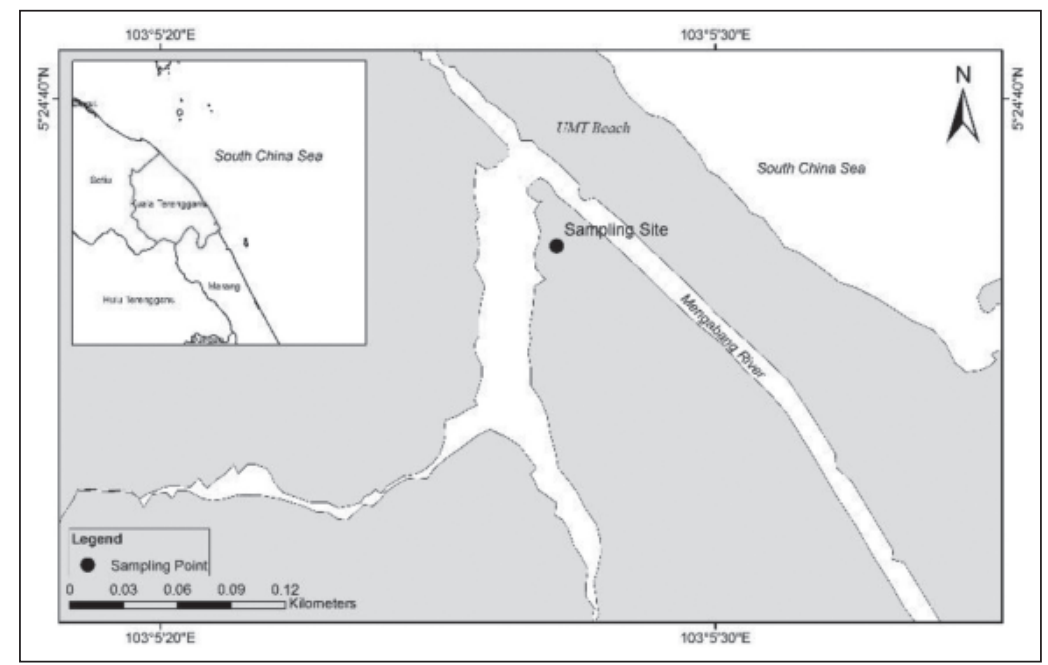

Fig. 1. Mangrove area in Universiti Malaysia Terengganu campus located along the Mengabang river and connected directly to the South China Sea. 
organisms such as bacteria from contaminating the culture. The remaining solvents on samples were rinsed using sterile distilled water. The sterile filter paper was used to dry the samples before the samples were placed onto the PDA media (with antibiotics). Full strength media was prepared for direct plating of leaf symptoms and half strength media for the pure colony and pure culture (Table 1). Antibiotic penicillin was added to the media to prevent any contamination from bacteria. All samples were incubated at room temperature $\left(27 \pm 2^{\circ} \mathrm{C}\right)$. Any fungi that grow out from the leaf samples were isolated onto the new PDA media to obtain a pure colony of fungus (Ravindran et al., 2012). The morphology characteristics of the fungi were identified under an Olympus compound microscope.

\section{RESULTS AND DISCUSSION}

\section{Mangrove diseases symptom}

A total of five symptoms were observed namely black leaf spot, grey leaf spot, leaf rot, sunken leaf blight, and anthracnose on the $R$. apiculata leaf (Figure 2). However, only two common symptoms appeared on the A. marina leaves: grey leaf spot and anthracnose. Although both mangrove species showed the same grey leaf spot and anthracnose symptom, the symptom sizes and appearance on each leaf were slightly different.

Physically, the $A$. marina leaf has thicker water storage tissue than $R$. apiculata and the cuticle layer of $A$. marina is rough compared to other mangrove species due to the presence of uniseriate epidermal hairs (Poompozil \& Kumarasamy, 2014). Therefore, those physical barriers on A. marina leaf may prevent spore attachment and/or delay germination of spores. The colonization of fungi begins as soon as the spores germinate and produce appressoria to penetrate the leaf tissue where then the fungal invasion will take over (Agrios, 2005). This invasion is depending on the fungi virulence, host susceptibility, and environmental conditions (Agrios 2005; Geeta, 2010). Thus, observation under SEM shown the presence of mycelia and conidia spores at the first stage of infection (attachment) before penetration (Agrios, 2005) (Figure 3). Salt concentration in $A$. marina leaf is higher than $R$. apiculata and this is an advantage to retard the fungal spore germination (Gregory et al., 2002).

\section{Morphology characteristics of isolates}

Results showed that a total of four fungi genera were successfully identified morphologically from five disease symptoms on both $R$. apiculata and A. marina. The leaves of $R$. apiculata were the highest in the number of fungi species that were invaded and isolated. However, the dominant fungus associated with mangrove leaves was identified as Pestalotiopsis sp. (leaf spot) and followed by Colletotrichum sp. (anthracnose). Each isolate was observed under a compound microscope at a magnification of $100 x$ to identify the genus of fungi. The summary description of the isolates as described in Table 2.

Pestalotiopsis sp. isolated from both black and grey leaf spot symptoms of $R$. apiculata and $A$. marina produced a dense and creamy white color

Table 1. Composition of Potato Dextrose Agar (PDA) media used for fungi isolation

\begin{tabular}{lcc}
\hline Material & Full strength & Half strength \\
\hline PDA Powder (20g dextrose, 15g agar, 4g potato starch) & $39 \mathrm{~g}$ & $19.5 \mathrm{~g}$ \\
Distilled water & $1 \mathrm{~L}$ & $1 \mathrm{~L}$ \\
Penicillin powder & $0.1 \mathrm{~g}$ & $0.05 \mathrm{~g}$ \\
\hline
\end{tabular}

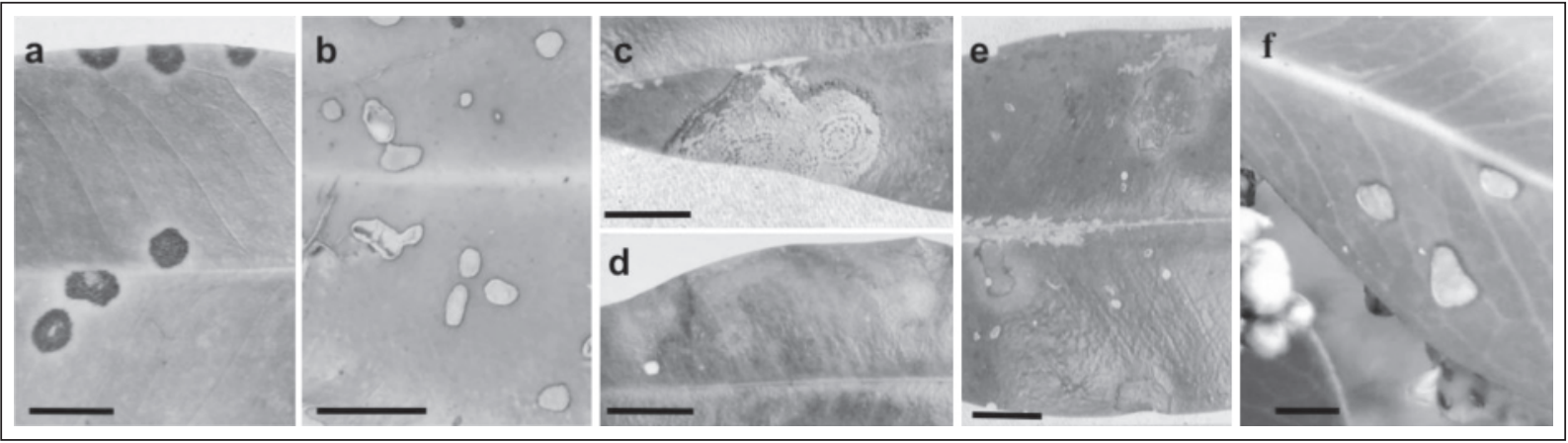

Fig. 2. Symptoms on leaves of Rhizophora apiculata (a-d) and Avicennia marina (e-f). Several symptoms on leaves observed were (a) black leaf spot, (b) grey leaf spot, (c) anthracnose, (d) sunken leaf blight like the early stage of anthracnose, (e) anthracnose with obvious margin, and (f) grey leaf spot. Black lines are scales at $1 \mathrm{~cm}$. 


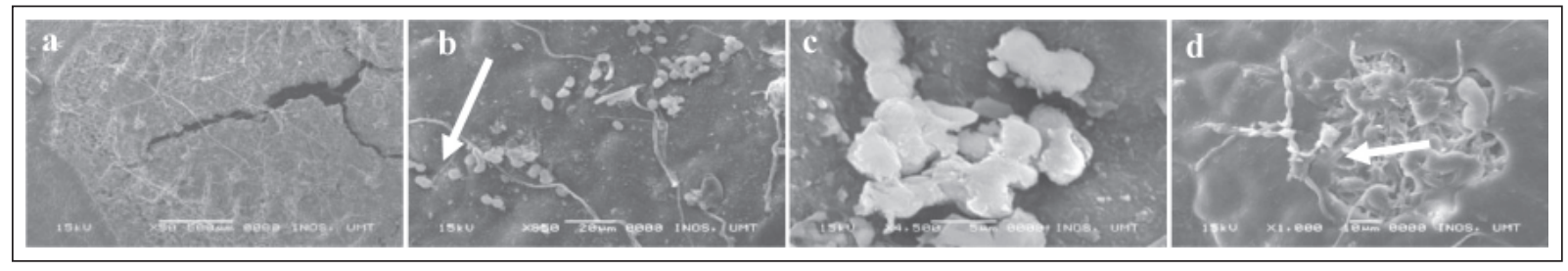

Fig. 3. Observation of fungal morphology characteristics on leaves surface under SEM showing (a) mycelia grows on the leaf lesion, (b) hyphae (arrow), (c) conidia, and (d) chain of microconidia (arrow).

Table 2. Summary of basic morphology of the fungi colony isolated from the symptomatic mangrove leaves of $R$. apiculata and $A$. marina that have been observed a) on a plate and b) under a compound microscope

\begin{tabular}{|c|c|c|c|c|c|}
\hline & Characteristics & Pestalotiopsis sp. & Curvularia sp. & Colletotrichum sp. & Rhizopus sp. \\
\hline \multirow{6}{*}{ 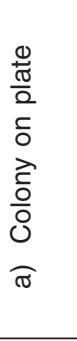 } & Form & Filamentous & Filamentous & Filamentous & Rhizoid \\
\hline & Elevation & Slightly raised & Convex & Convex & Raised \\
\hline & Margin & Filiform & Filiform & Entire & Entire \\
\hline & Color & Creamy white & Light brownish & $\begin{array}{l}\text { Creamy white to } \\
\text { creamy orange }\end{array}$ & $\begin{array}{l}\text { Light to dark } \\
\text { green }\end{array}$ \\
\hline & Fruiting body & Black color & Absent & Orange & Absent \\
\hline & Growth rate & Fast & Medium & Medium & Fast \\
\hline \multirow{4}{*}{ 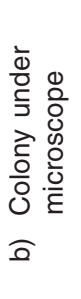 } & Mycelia & Dense & Dense & Dense & Very dense \\
\hline & Shape of conidia & $\begin{array}{l}\text { - Elongated fusiform } \\
\text { - Three median cells }\end{array}$ & $\begin{array}{l}\text { - Elongated fusiform } \\
\text { - Three median cell }\end{array}$ & Hyaline cylindrical & Conidia absent \\
\hline & Hyphae & Septate & Septate & Septate & Septate \\
\hline & $\begin{array}{l}\text { Other } \\
\text { characteristics }\end{array}$ & $\begin{array}{l}\text { Presence of two } \\
\text { apical appendages } \\
\text { on the conidia }\end{array}$ & $\begin{array}{l}\text { Multinucleated } \\
\text { segmented conidia }\end{array}$ & $\begin{array}{l}\text { Presence of acervuli } \\
\text { covering the fruiting } \\
\text { body case }\end{array}$ & $\begin{array}{l}\text { Presence of } \\
\text { apophysis }\end{array}$ \\
\hline
\end{tabular}

of mycelia with black subepidermal fruiting body structure known as acervuli [Figure $4 \mathrm{a}$ (i and ii)]. The growth rate was fast as the mycelia of the culture almost covered the whole petri dish after 10 days of incubation period at room temperature. It has several general characteristics such as the presence of median cell (pigmented), apical and basal appendages, or hairs (Maharachchikumbura et al., 2011). The three-median cell with two apical appendages and one or almost absent of basal appendage was pigmented, brownish, elongated fusiform of conidia [Figure $4 \mathrm{a}($ iii)]. Most conidia length ranged from $12 \mu \mathrm{m}$ to $20 \mu \mathrm{m}$ but there was conidia size about $35 \mu \mathrm{m}$ and some still bearing on the branching hyphae [Figure 4a (iv)].

Curvularia sp. isolated from sunken leaf blight symptom was slow growth than other fungi. The margin of the mycelia was filiform with a cottony texture whereas, at an early stage, the pigmentation was white and brownish as it ages [Figure $4 \mathrm{~b}$ (i and ii)]. The conidia shape almost similar to Pestalotiopsis sp. but the conidia length ranging from $25 \mu \mathrm{m}$ to $35 \mu \mathrm{m}$ and without appendage at both apical and basal end of the conidia [Figure $4 b$ (iii)]. Some of the conidia were straight to slightly curve and the hyphae are septate and some have branches [Figure 4b(iv)].

The isolates of Colletotrichum sp. from anthracnose symptom produced creamy white and robust mycelia [Figure $4 \mathrm{c}(\mathrm{i}$ and ii)]. The colony appearance was fluffy that raised upward forming like a dome-shape. It produced light orange-colored fruiting bodies of acervuli that contained an abundance of similar in shape and size of conidia. Colletotrichum sp. produced hyaline cylindrical shape conidia with a length ranging from $11 \mu \mathrm{m}$ to $18 \mu \mathrm{m}$. It is one of the fungi that could be easily distinguished from other fungi with the presence of acervuli [Figure 4c(iii and iv)].

The rapidly growing colonies were isolated from leaf rot symptoms and were identified as Rhizopus species. It only took 5 days for Rhizopus sp. to cover the whole agar plate incubated at room temperature. The pigmentation was from light green to dark as they produce spores that are similar to cotton candy in texture [Figure $4 \mathrm{~d}(\mathrm{i}$ and ii)]. Colony produced a round shape of sporangium on top of the apophysis with a diameter length was about 8 $\mu \mathrm{m}$ [Figure $4 \mathrm{~d}(\mathrm{iii})]$. The hyphae were wider than other fungi, $3 \mu \mathrm{m}-3.5 \mu \mathrm{m}$ and there was an early 


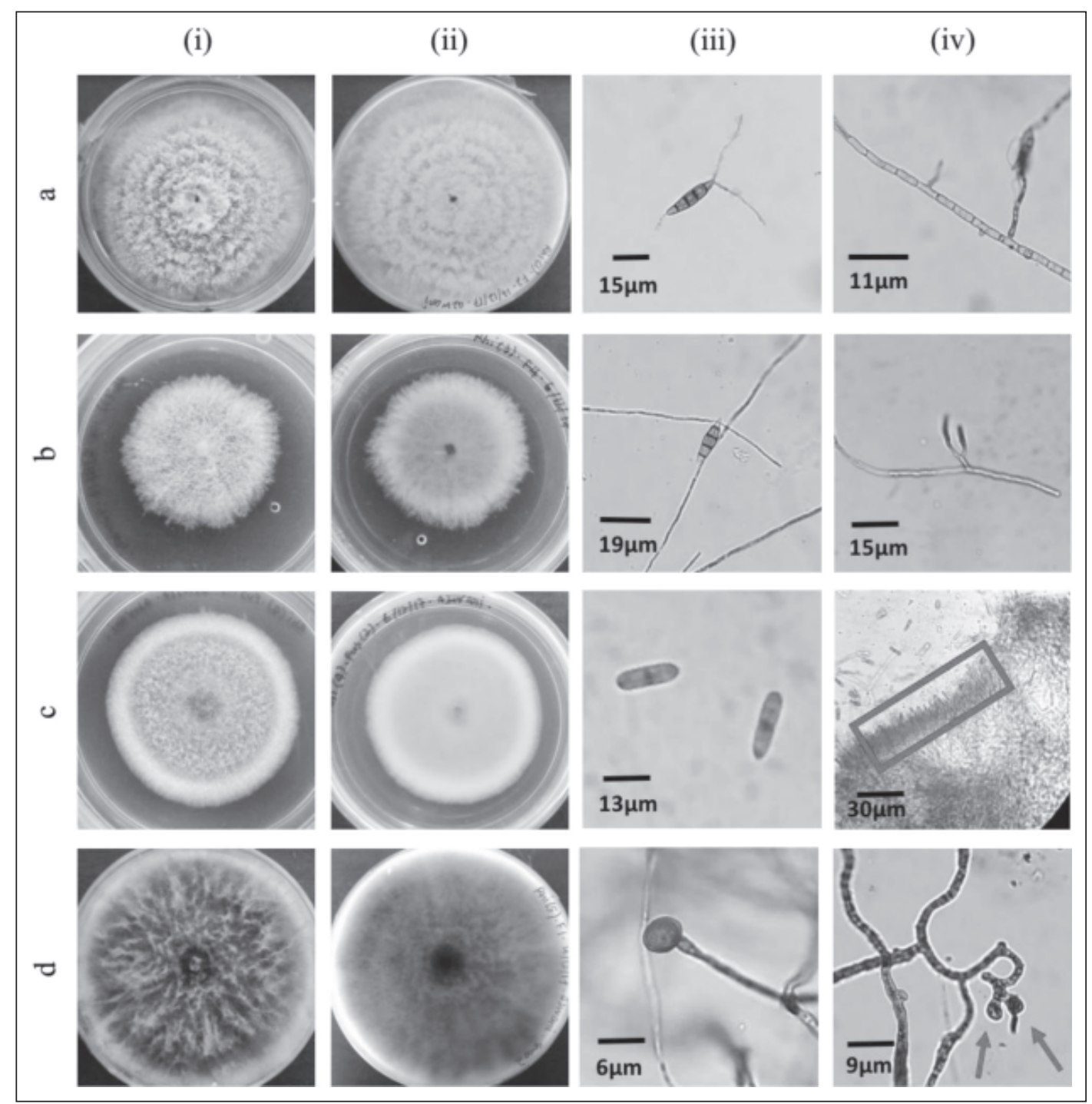

Fig. 4. Morphological characteristics of isolated fungi from foliar diseases of mangroves. On agar plate; (i) the top surface and (ii) bottom surface of (a) Pestalotiopsis sp. with a distinguish microscopic of (iii) conidia and appendage and, (iv) septate hyphae; (b) Curvularia sp. with (iii) conidia and, (iv) branching hyphae; (c) Colletotrichum sp. with (iii) cylindrical conidia and, (iv) acervuli; (d) Rhizopus sp. with (iii) sporangium and (iv) apophysis. Cultures were observed under $100 \mathrm{X}$ total magnification.

stage of apophysis was observed where it will grow longer forming a sporangiophore to support the sporangium on top of the stolon [Figure 4d (iv)].

Rhizophora apiculata was quite susceptible to foliar disease especially when all four fungi were invading the leaves compared to A. marina that had been invaded by only Pestalotiopsis sp. and Colletotrichum sp. These fungi species are well-known in the crop that cause devastating plant disease (Agrios, 2005). Among the leaf symptoms observed, anthracnose disease caused by Colletotrichum sp. is commonly known to affect a wide range of crops such as chili plant (Oo \& Oh, 2016) and mango trees (Ismail et al., 2015). Rossi et al. (2017) had reported on a similar fungus, Pestalotiopsis sp. causing leaf spot symptom on R. mangle.
This study has confirmed the presence of foliar diseases namely black leaf spot, grey leaf spot, leaf rot, sunken leaf blight, and anthracnose caused by fungi at mangroves area in the UMT campus. However, further work is essential to confirm fungi pathogenicity and to understand its life cycle in the mangrove ecosystem. On top of that, a molecular approach is required to confirm the species.

\section{ACKNOWLEDGEMENTS}

We express our gratitude to the Faculty of Science and Marine Environment (FSME) and Laboratory for Pest, Disease, and Microbial Biotechnology (LAPDiM) for the financial and technical support. Thanks to Nur Ain Shakirah, Aliah Amira, Fatin 
Najwa, and Addin Malik for their field assistance throughout the fieldwork.

\section{REFERENCES}

Abdullah, M.M., Bachok, Z. \& Muslim, M. 2010. Litterfall dynamics in the Chukai-Kemaman Mangrove Forest. Proceedings of the Universiti Malaysia Terengganu 9th International Annual Symposium on Sustainability Science and Management. Malaysia. 114: 211-216.

Agrios, G.N. 2005. Plant Pathology. 5th Ed. Dana Dreibelbes. $952 \mathrm{pp}$.

Alias, S.A., Zainuddin, N. \& Jones, E.G. 2010. Biodiversity of marine fungi in Malaysian mangroves. Botanica Marina, 53(6): 545-554.

Alongi, D.M. 2009. The Energetics of Mangrove Forests. 1st Ed. Springer Science + Business Media B.V. $221 \mathrm{pp}$.

Geeta, S. 2010. The Fungi. 2nd Ed. Alpha Science International Ltd. 298 pp.

Gregory, S.G., Mónica, M.C. \& Enith, R. 2002. Fungal diversity and plant disease in mangrove forests: Salt excretion as a possible defense mechanism. Oecologia. 132: 278-285.

Horst, R. 2008. Plant disease and their pathogens. In: Horst R. (Eds.). Westcott's Plant Disease Handbook. Springer, Dordrecht.

Ismail, A.M., Cirvilleri, G., Yaseen, T., Epifani, F., Perrone, G. \& Polizzi, G. 2015. Characterization of Colletotrichum species causing anthracnose disease of mango in Italy. Journal of Plant Pathology, 167-171.

Jones, E.G. \& Kuthubutheen, A.J. 1989. Malaysian mangrove fungi. Sydowia, 41(19): 161.

Jones, E.B.G. \& Hyde, K.D. 1988. Methods for the study of manglicolous marine fungi. In: Mangrove Microbiology; Role of Microorganisms in nutrient cycling of mangrove soils and waters (Eds. A.D. Agate., C.V. Subramanian and $\mathrm{H}$. Vannucci), 9-27.

Jones, E.B.G. \& Hyde, K.D. 1990. Observations on poorly known mangrove fungi and a nomenclatural correction. Mycotaxonomy, 37: 197-201.

Kohlmeyer, J. 1969. Ecological notes on fungi in mangrove forests. Transactions of the British Mycological Society, 53: 237-250.

Kothari, V., Patadia, M. \& Trivedi, N. 2011. Microwave sterilized media supports better microbial growth than autoclaved media. Research in Biotechnology, 2(5): 63-72.

Larsen, H. 2017. Plant Pathology, Coryneum Blight Fact Sheet No. 2.194, Colorado State University.
Lee, H.K.O. \& Hyde, D.K. 2002. Phylloplane fungi in Hong Kong mangroves: evaluation of study methods. Mycologia, 94(4): 596-606.

Lucas, G.B. \& Campbell, L. 2012. Introduction to Plant Diseases: Identification and Management. Springer Science \& Business Media. 364 pp.

Maharachchikumbura, S.S., Guo, L.D., Chukeatirote, E., Bahkali, A.H. \& Hyde, K.D. 2011. Pestalotiopsis-morphology, phylogeny, biochemistry, and diversity. Fungal Diversity, 50(1): 167.

Mcleod, E., Chmura, G.L., Bouillon, S., Salm, R., Bjork, M., Duarte, C.M., Lovelock, C.E., Schlesinger, W.H. \& Silliman, B.R. 2011. A blueprint for blue carbon: toward an improved understanding of the role of vegetated coastal habitats in sequestering $\mathrm{CO} 2$. Frontiers in Ecology and the Environment, 9(10): 552-560.

McMillan, I.I. 1964. Annual population changes in California quail. The Journal of Wildlife Management, 702-711.

Oo, M.M. \& Oh, S.K. 2016. Chilli anthracnose (Colletotrichum sp.) disease and its management approach. Korean Journal of Agricultural Science, 43: 153-162.

Poompozhil, S. \& Kumarasamy, D. 2014. Leaf anatomical studies on some mangrove plants. Journal of Academia and Industrial Research, 2(10): 583-589.

Purkayastha, R.P. \& Pal, A.K. 1998. SEM studies on mangrove rust of Sundarbans, Eastern India. Mycological Research, 102(6): 692-694.

Purwaka \& Siregar, C.A. 2002. Biomass karbon pada hutan tanaman mangrove. Laporan hasil penelitian. Pusat Penelitian Hutan dan Konservasi Alam.

Ravindran, C., Naveenan, T., Varatharajan, G.R. \& Rajasabapathy, R. 2012. Antioxidants in mangrove plants and endophytic fungal associations. Botanica Marina, 55: 269-279.

Rossi, R.E., Layman, C.A. \& Ristaino, J.B. 2017. A species of Pestalotiopsis identified infecting red mangrove in The Bahamas. In 2017 APS Annual Meeting. APSNET.

Siikamäki, J., Sanchirico, J.N. \& Jardine, S.L. 2012. Global economic potential for reducing carbon dioxide emissions from mangrove loss. PNAS 2012.

Steven, V. 2012. The Life of a Leaf. The University of Chicago Press, Chicago.

Stevens, F.L. 1920. New or noteworthy Porto Rican fungi. Botanical Gazette, 70(5): 399-402. 